\title{
Data\&Society
}

\section{Understanding Intelligent Systems}

by Alex Rosenblat, Tamara Kneese, and danah boyd

Data \& Society Working Paper, October 8, 2014

Prepared for: Future of Work Project supported by Open Society Foundations

\section{Brief Description}

Throughout the $20^{\text {th }}$ century, science fiction portrayed a robotic future in both utopian and dystopian ways. The reality of automated systems, intelligent systems, and "robots" in the workforce, however, is much more mundane, even if it is undoubtedly disruptive. The same set of technologies that empower employees to be more effective or bear less physical risk can displace a workforce in other sectors, or undermine economic systems. Unrepentant fear and hope often obscure the complex socio-technical dynamics of intelligent systems in the workplace, yet moving beyond this is critical to developing the right framework for navigating the development of such systems. This is especially important at a moment when the results of a recent canvassing survey of widely-quoted technology builders, analysts, and other insightful figures by the Pew Research Center (Smith \& Anderson, 2014) on robots prompted Walter Frick (2014) at the Harvard Business Review to exclaim that, "Experts have no idea if a robot will steal your job."

What everyday people think robots should do occupationally is generally stratified into three questions, according to researchers at Stanford: "1) Can robots perform various occupations as well as humans?,2) Regardless of capabilities, which occupations should robots be permitted to do?, and 3) Should certain occupations be solely human or solely robotic, or are there occupations that should be inhabited by both humans and robots?" Unsurprisingly, their research on attitudes toward robots concluded in favor of an uneasy balance on the spectrum somewhere between technology as utopian and technology as dystopian: “...people will feel more positively toward robots doing jobs with people rather than in place of people" (Takayama, Ju, \& Nass, 2008, p. 1). To some degree, technological developments in human-machine interaction strive to incorporate this humanizing mediation toward what has been termed the 'cyborg society' by creating robotic designs that fit well, like wearable devices, or that seem cute and thus harmless. When a robotic technology act in place of a part of a human, like an artificial limb replacing an amputated leg, it is hailed as a great advance, and yet the same possibilities for human-replacement evokes dystopian fear and anxiety when it comes to jobs that a human (or a human leg) can do.

Innovators have a longstanding history of developing tools to help automate activities, although the rate at which innovative technologies can cause major disruptions is sometimes inflated. As professor Ryan Calo (2014), a specialist in 
cyberlaw, observes, "The mainstreaming of robotics is not as sudden as it might seem. Artists and hobbyists-early harbingers of the computer revolution-have turned to robotics in droves" (p. 14). While a factory doesn't automate all of its functions at once, there can be a gradual displacement of workers that stems from automation, and the questions become: where do they go, what do they lose, and what possible gains do they experience from having their work supplemented by intelligent systems? The answers can be as variable as the values embedded in the place or task workers are displaced from, but there are always more questions: does a worker at an auto factory whose job is taken over by intelligent systems miss the specific job, the tools he works with, his worksite, the industry, the guarantee of income, health insurance, job security, a sense of identity he has developed around the type of work he does, or any other multifaceted concerns that comprehend loss or change? What would suffice to remunerate people for the dispossession they experience?

We often associate job loss through automation with blue-collar work, but the growth of digital labor has affected white-collar jobs in parallel ways, in part because the protections that grow up around the jobs that are lost are not seamlessly re-mapped onto the new types of jobs that develop. Lost protection and familiarity shakes up our ongoing belief-and raises our suspicions-about what the future holds. When a good job, for instance, is no longer accessible or available because that job has been made redundant or because robots can take care of the functions formerly carried out by workers, this can represent a challenge to the societal values we hold that underwrite our continued participation and belief in technology as inherently progressive. When the face of job opportunities shift in the advent of technologically-mediated changes, it's important to consider which values are coming under scrutiny, and what is leading to a sense of disruption.

\section{Fuzzy Probability}

Artificial intelligence (AI) refers to technology with mechanisms that have computational intelligence, are cognizant, and respond to the needs and multifaceted intelligence of humans. Not every computational ability is considered intelligent; nor can all intelligent machines simulate, replicate, or imitate functions that human intelligence produces or executes. Intelligent systems operate by using probabilistic notions to sense, detect, and execute certain actions, even if they have the appearance of exact or precise action. This is a common misunderstanding, and it feeds into the fear that utopian / dystopian tropes rely on when they animate discussions about robots taking over all of the functions humans currently carry out.

Robots, much like people, are calculating probabilities from a series of informational inputs that are computed to calculate the probabilities of varying outcomes based on multi-factored inputs, whether that is about how to identify one door from an identical set, or what the optimal move is in a chess game. In order to design intelligent systems that can think computationally, human knowledge and 
experience has to be devised as a mathematical representation, and that has to account for gaps in our knowledge as well as the difficulty of integrating human knowledge with mathematical and statistical models to generate intelligent decisions (MoshtaghKhorasani et al., 2009). In a parallel example, physicians can offer very little certainty in their assessments, but they can offer probabilistic opinions about, for instance, the likelihood that one treatment will be more effective than another, or that a diagnosis is more likely than its alternatives (Moshtagh-Khorasani et al., 2009). The availability of intelligent systems often creates the expectation that a more perfect diagnoses or solution is forthcoming from physicians, but that obscures the probabilistic mechanisms that generate possible diagnoses or solutions, rather than precise and perfect knowledge.

The challenges of product design and engineering also factor into what the end-user receives, and that may or may not meet their needs in ways that are efficient, effective, or optimal. For example, one of the challenges of developing more intelligent systems is creating software that is more context-aware, such that it can adapt to changes in its user's behavior, location, or other context-shifts (Lee, 2007). For example, if you query a restaurant or a location through your smartphone, the software it relies on might produce a route that directs you from your current location to the one you have just queried, automatically. The identity of the user, their activity, the time, and their location are some of the informational inputs that create the baselines for context awareness (Lee, 2007, p. 4). However, context is challenging for computers to detect compared to context-aware humans, and it's not always clear if the human user or the system is at fault for contextual misunderstandings (Lee, 2007). For example, if a Roomba doesn't recognize the rug on the floor and gets stuck, is that the fault of the intelligent system or the intelligent user who didn't understand the Roomba's limitations (Lee, 2007, p. 17)?

Often, the role that technology plays is supplementary to our work, but it doesn't necessarily make people or their jobs redundant or easily replaceable, in part because the complexity of robotic systems varies, as do the quandaries that they are designed to address. Moreover, robotic systems evoke a certain techno-utopianism that belies the normalization of robotic systems in everyday life, such as the ubiquity of smartphones. Part of this has to do with the vocabulary of intelligent systems, in contrast with, for instance, the 'Internet of Things', or other trendy doctrines like 'smartification' that use a softer, more familiar wording. We know smart when we see it, but we don't know what to make of a robot and its artificial intelligence.

\section{Which technologies feel disruptive?}

The types of technologies that create disruption or replace jobs range from Google Glass and Amazon's delivery drones to less sensational automated tollbooth systems or automated teller machines (ATMs). While the technologies may have already existed in various forms for some time, once they manifest in certain ways that offend or upset public sensibilities, they are considered disruptive, even if they offer solutions to 
problems that have been articulated by consumers who want more from their technology companies. For instance, if a consumer wants a product delivered to their door in two hours from an Amazon warehouse (McClelland, 2012), a drone might be a more palatable solution to quick deliveries than hiring humans to perform work at exploitative speeds or in abusive conditions. Still, in this scenario, laborers are being made redundant by the drones rather than exploited without them (Tufekci, 2014). As it is, workers are advised to retrain or go back to school, but as former New York Mayor Michael Bloomberg advised, in response to Facebook CEO Mark Zuckerberg's push for everyone to learn how to program, "You're not going to teach a coal miner to code" (Fehrenbacher, 2014).

The prompt that hastens governmental oversight of a disruptive and innovative technology that also makes certain jobs redundant tends to happen around the rhetoric of safety rather than job redundancy. The Federal Aviation Administration (FAA) banned commercial drones earlier this year, citing privacy and safety concerns (crashes, aircraft interference, etc.), although the ban was struck down by a judge and is currently under appeal. Meanwhile, the limits of the acceptable use of drones are being tested out: realtors in Des Moines have been offering potential buyers birds-eye-view footage they take of real estate using quadcopters, for example, which is perceived as interesting and "cool" by buyers and realtors alike (Aschbrenner, 2014). However, even as the fun uses of robotic technology helps to normalize it, concerns about safety and privacy emerge in response to technology that disrupts norms society holds. Celebrity Kanye West recently testified on the fears he has that reporters might resort to using drones to photograph him or his family in a trial about an altercation between him and a member of the paparazzi:

Wouldn't you like to just teach your daughter how to swim without a drone flying? What happens if a drone falls right next to her? Would it electrocute her? Could it fall and hit her if that paparazzi doesn't understand how to remote control the drone over their house? (Hernandez, 2014).

As West points out, what is a reasonable barrier to innovative technology? When do concerns about safety and privacy outweigh our freedom to have and use robotic technologies? One drone operator who was flying his device at a beach was assaulted by a woman who was offended by the possibility of beach-goers being recorded in their bathing suits, and of course, the assault was captured on video (McNeal, 2014). Cameras aren't new, but the drone represented a breach of etiquette, privacy, and an affront to norms of conduct, in part because the technology in that flying form is not yet ubiquitous. The harms it represents, and our ways of determining the scope of its actions, are not readily available.

When innovative technology, systems, or products are developed, they tend to disrupt not only familiar ways of doing things, but also wreak temporary havoc on the laws and policies designed to regulate their predecessors. This disruption creates a space for debating the impact that we anticipate these products and systems to have, and 
sometimes the potential for harm requires certain precautions to be considered. While these debates are only emerging around intelligent systems, we already see them fully realized in other areas of technological innovation, such as current debates around Google Glass (Burns, 2014).

Whether the technology is Google Glass, drones, or something else, we have to weigh the potential benefits and consequences, and design systems for ensuring a favorable balance between the two. We understand, for instance, that medicines are good, but they can also do real harm if their functions are ill understood or not monitored carefully. Subsequently, it is required that many pharmaceutical drugs be monitored by physicians so that their potential harms can be offset by educated supervision. Safety is considered an intuitively good reason for taking some action to support or prohibit the development of intelligent systems, but how that risk-averse concern is co-opted to normalize technology is a process that interplays with a host of other values. For example, working in a tollbooth may be a perfectly acceptable job until the technology exists to replace it. At that point, the rhetoric around safety, and how tollbooth workers can suffer from higher rates of cancer from being exposed to so much diesel exhaust (Canadian Centre for Occupational Health and Safety, 2012), becomes the guiding, if paternalistic, logic to dismantling that occupation. As researcher Leila Takayama and colleagues write, "Robots are frequently envisioned as fulfilling jobs that have the three Ds: dirty, dangerous and dull. In this model, the archetypical robot job is repetitive physical labor on a steaming hot factory floor involving heavy machinery that threatens life and limb" (Takayama, Ju, \& Nass, 2008, p. 1).

The very risks that make robotic interventions seem inviting can cause the workers who are subjected to them recoil, as these interventions may challenge the sense of identity that is wrapped up in their occupation. For example, sociologist Karen Levy (2014) documents how truckers are often men who have left the more automated, supervised conditions of a factory workplace to take to the road, where they can be autonomous, independent, and manly: they are "asphalt cowboys," not cowed workers (p. 9). They resist attempts to regulate their activities, like the introduction of Electronic On-Board Recorders (EOBR) that prospective government legislation will make mandatory to track truckers' hours in ways that they can't fake with their paperlogbooks (known as 'coloring books' for the lack of seriousness with which these logs are treated) (Levy, 2014, p. 5). This tracking is meant to enforce laws that limit drivers' hours on the road so that they don't drive dangerously or crash due to fatigue. This logic is furthered by cases like the overworked Walmart truck driver who slammed into comedian Tracy Morgan's tour vehicle, leading the injured star to sue Walmart for damages (Smith-Spark \& Sung, 2014). While the intent of this legislation is bound up in the rhetoric of safety, it ignores a lot of the fears that electronic monitoring technologies evoke in truckers about the prospects that they will lose their occupational autonomy (Levy, 2014, p. 7). These EOBRs never measure only time - they encapsulate bundled services that can track anything from fuel efficiency to the driver's whereabouts when he is off-duty or on his way home (Levy, 2014, p. 7). In this case, technologies feel 
disruptive and invasive to workers and worker autonomy, and at the same time, protective of business and public interests, particularly in public safety.

The progressive technologies that make certain job models obsolete, are touted to be vehicles for job creation in other ways. Uber, for example, is a technology company that provides the infrastructure for drivers to contract with customers outside of the traditional dispatcher-car service model. Uber has also partnered with Google to try and bring self-driving cars to the transportation service marketplace (Newton, 2014), which speaks for its intentions to remove or reduce the roles of workers from the service it provides. It has teamed up with other third-parties as well to integrate its services further, potentially with hotel and airline apps, such that when a user makes a travel reservation, an Uber car is automatically arranged to take them where they need to go (Constine, 2014): to illustrate the point, Tech Crunch came up with a photo of a manshaped robot performing a street-hail of an Uber car. Where a user previously had to lift a finger (or a whole arm) to make these arrangements, an intelligent system can perform those functions automatically. A button that e-hails a driver isn't a jetpack, but it can still stoke fears about unsustainable forms of employment, while at the same time spurring hopes that technology will deliver all sorts of new conveniences.

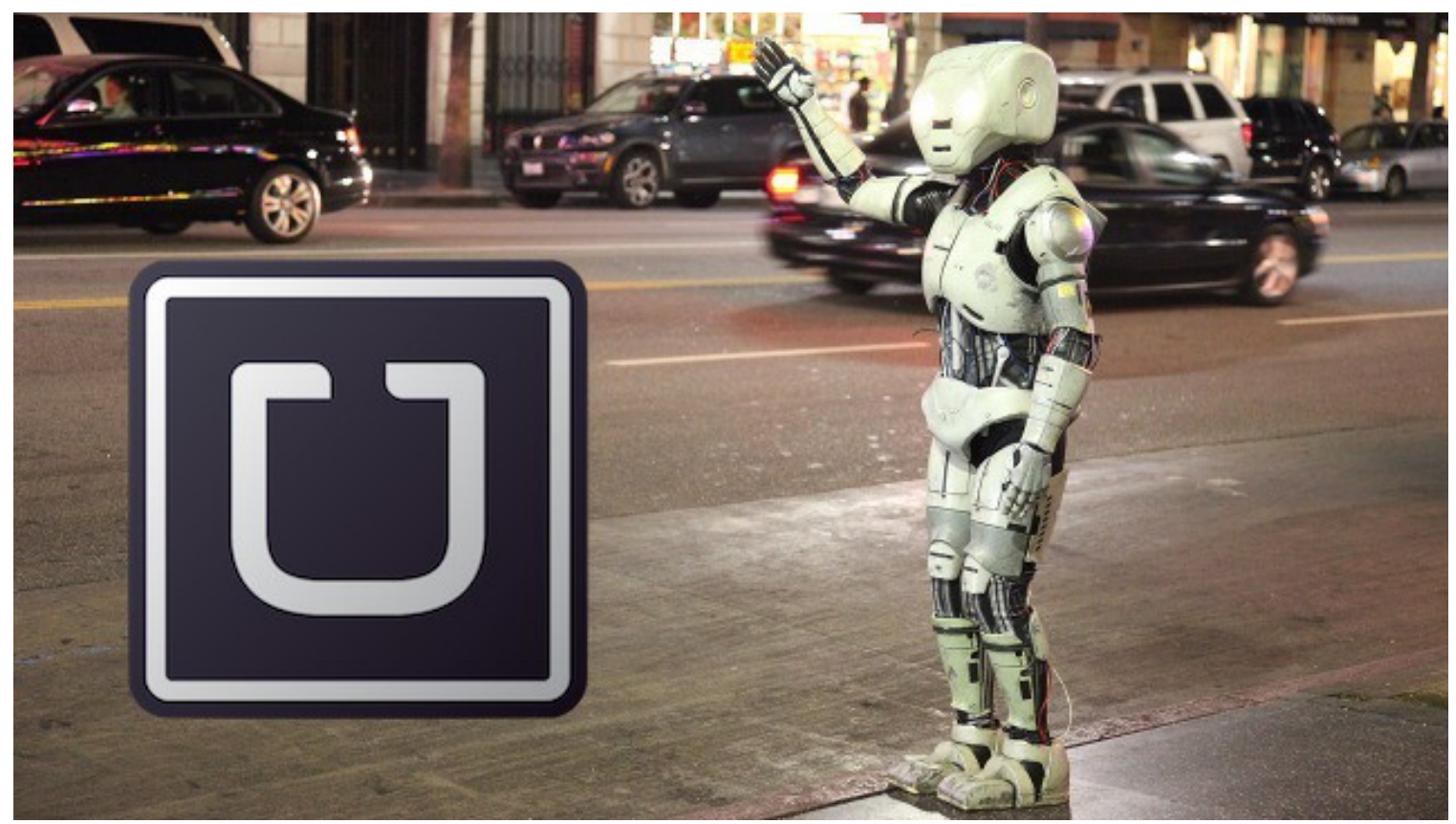

Photo from Tech Crunch (Lawler, 2014).

\section{Technological Advances and Conflicting Values}

There are backlashes to the notion that intelligent systems will replace workers. In contrast to the fears that robots will replace fast food employees (CNN Wire, 2014), some workers have changed tack with the shifting winds by turning away from fast-paced or corporatized labor and products and towards slow-paced artisanal labors of love. In an ethnographic study of craft cheesemakers in Wisconsin and Vermont, anthropologist 
Heather Paxson (2012) documents how dairy farmers whose traditional family business is making cheese and well-educated urbanites who either had opportunities to leave agriculture behind or are completely inexperienced farmers take up craft cheesemaking. The former sometimes use artisanal cheesemaking to retreat against corporatized dairy farming practices, while the latter are often motivated to retreat from urban job markets and city living in a sentimental return to the land-and their products appeal to consumers who embody that sentiment, too. However, Paxson (2012) observes that the “...idealization of the working landscape can paper over real economic differences among working farmers and artisans" (p. 21). In other words, workers may be doing jobs for reasons other than making a good living, like having flexibility or autonomy, or working with their hands in a variety of tasks, but these reasons become explicit in part because these labors are not very profitable on their own, and they have to be communicated to consumers in ways that sell sentiment, not just dairy products. Jobs that are built on what Paxson describes as 'economies of sentiment' (p. 65), and which inscribe a sense of social good, self-fulfillment, and emotional labor onto work, are potentially an opportunity to repossess some of the social values that are lost when intelligent systems automate functions previously performed by workers who took pride in their skills. However, jobs built on sentiment also have limited potential for restoring the hallmarks of financial security, like retirement savings (Paxson, 2012, p. 71).

Our interest in economies of sentiment, which are evident in the proliferation and popularity of handmade, artisan crafts, and in the flourishing 'peer' or 'sharing' economy is the natural corollary to our obsession with automation. What does it mean to work with our hands, instead of letting robots do work automatically? How does automation impact the conditions and opportunities for labor? In one such response to this question, Sociology professor Zeynep Tufekci (2014) asks us to question whether automation is supplementing jobs to the extent that people are paid too little for the remainder of their labor to live sustainably or securely. She writes,

For example, it was nurses who used to take blood pressure. Then it became nurse's assistants or physician's assistant-much lower-paid jobs that require less training. Then came machines that perform a reasonable job taking your blood pressure, and the job became even less skilled. More and more, you only see your doctor for a few minutes so that her highly-paid time is dedicated to only that which she can do-is licensed to do-, and everything else is either automated or done by someone paid much less.

Sometimes, the automating functions that improve business performances can make life unsustainable for employees. What happens when scheduling software that automates the conditions of labor begins to exert huge amounts of control over workers' lives while, at the same time, lowers their quality of life? The New York Times covered this issue in detail, highlighting the story of a Starbucks barista who found that she had no control over basic family needs because the scheduling software determined when she would work in ways that left her scrambling to find childcare and arrange for simple 
human needs like sleep (Kantor, 2014). It is important to recognize that software doesn't act independently of company policies. For example, the company Favor, which operates an app to deliver items from local restaurants and stores, hires workers in shifts to pick up the food and messenger it to customers. Workers are paid in tips plus a percentage of the fees involved in each order, but the company offers some predictability to an otherwise precarious source of income by topping up workers whose tips are too low to cover the minimum wage of hourly work, and by allowing workers to schedule shifts a week in advance (Singer, 2014).

There has been a lot of media hype surrounding the use of automated systems to hire employees or to make financial decisions. A recent study demonstrated that algorithms are better equipped to make decisions than humans, often yielding better results (Kuncel, Klieger, \& Ones, 2014). Managers are still advised, however, to utilize human intuition and eye contact to make a final judgment call. For example, automated systems are used to filter potential employees, but humans still make the final decision. Of course, some businesses are pushing for deeper involvement by intelligent systems. For example, a venture capital firm hired an algorithm to its board of directors (Huffpost Tech, 2014). The situation is not quite as picaresque as one would imagine: "[The head of the company] added in an interview that the set up of board meetings won't literally be humans and one laptop sitting around a table, but said its opinions will be given equal weight" (Huffpost Tech, 2014). While actively appointing AI to a corporate position is not a common phenomenon, algorithms are increasingly being use by managers in a wide variety of sectors in order to perform everyday tasks.

The alternative modes of employment are limited in what they can offer by way of protections for laborers, or for sustainable lifestyles, but they bring up the same questions that robotics and utopian and dystopian narratives evoke about our new way of life: what values should society be optimizing for? When do efficiency and control in the workplace, the hallmarks of automation, become dehumanizing, and when are their opposite features-flexibility and DIY, at your own pace labor-unsustainable?

\section{$\underline{\text { Robot Bosses and Friends }}$}

Intelligent systems come in many aesthetic forms. While some AI are made to resemble humans, this can induce the Uncanny Valley effect or invoke cautionary tales of almost-human robots, like the too-perfect-to-be-human, manicured women featured in Ira Levin's The Stepford Wives (1972), or Philip K. Dicks's androids who think they are human in Do Androids Dream of Electric Sheep? (1968). Other systems are designed to look more like the beloved robots of Hollywood Sci-Fi interpretations of AI, like R2-D2 in the beloved movie Star Wars (1977). Although most science fiction relishes anthropomorphized robots, there are some stories where intelligent systems have an impact without even being visible; in the world of Stanislaw Lem's Solaris (1961), a deeply intelligent, sentient planet has the ability to drive humans mad. Today, real intelligent systems come in many forms, intersecting with everyday life in a wide 
variety of ways. In some cases, they are our direct managers; in others, they are our domestic servants, and in still other cases, they are just random acquaintances we encounter as we go about our day.

Some robots, however, do register as living entities, and have the potential to inspiring empathy in humans. The Uncanny Valley is a term coined in 1970 by a Japanese roboticist named Mashahiro Mori. According to Mori, humans have more empathy for AI that looks human, but only up until a certain point (Kotler, 2014). People find it disturbing when AI too closely resembles the human form, but somehow misses the mark. A human interacting with or viewing a robot can recognize that something feels off or not right. Recently, funding from DARPA and USC's Center for Creative Studies was used to create Ellie, the first robot therapist, in order to treat soldiers with PTSD (Kotler, 2014). While robots that look too much like actual humans generally repulse people, this is not the case with Ellie. In fact, people seem more willing to talk openly with a robot shrink than they do with a human one. In turn, Ellie is able to track subtle changes in human facial expressions, body language, and vocal tone, allowing her to read emotions and provide this information to human therapists who wish to flag depressed or suicidal patients (Spiegel, 2013). These robot therapists, however, are not intended to replace human ones: "She's just there to offer insight to therapists, Morency says, by providing some objective measurements" (Spiegel, 2013). Still, even if replacement is not the intention, is it a potential unintended consequence of this kind of automation?

While Ellie closely resembles an actual human woman, there is also a trend towards robots that are simply cute. Canadian researchers recently produced HitchBot in order to see how far cuteness would take AI. The robot is programmed to hitchhike: "It looks sort of like a gum-ball machine with a bright LED smile and yellow rubber boots. If you talk to it, it'll ask you for a lift, and maybe to bum a charge off your car's cigarette lighter. So far, people are eager to help it out" (Dzieza, 2014). Designing cuter robots mean that humans are more trusting and are more likely to want to engage with the AI. Even Google, for example, has designed an adorable self-driving car, replete with a smiley face (Lowensohn, 2014). Cute robots are being designed for household use as well, approximating something along the lines of Rosie the Robot on the animated series The Jetsons. Jibo, which its developers call "the world's first family robot," can take care of the family's electronic needs, connecting them to all of their various devices and taking phone messages through the household's Wi-Fi. Jibo is able to do more than this, though, and can take family photographs, recognize individual members of the family, and even read stories to young children (Hodson, 2014). While it is unlikely that these adorable household robots will replace nannies and housekeepers (or the free domestic labor traditionally provided largely by female household members) in the near future, the potential use of robots to complete household tasks has long been a source of desire. Although existing robotic cleaners like the Roomba do little other than roam the house attempting to vacuum, one vision for domestic robots is that they will be well equipped to monitor household activity more generally. Yet, this raises serious ethical questions 
for roboticists: "Would it be appropriate, for instance, for Jibo to announce that the senior family member he has been watching has fallen down and cannot get up? We're going to have a really interesting dilemma about when a robot can violate privacy to save a life" (Hodson, 2014).

Beyond privacy-related ethical questions, what does it mean if robots do in fact replaced certain kinds of human labor? What does that mean in affective labor sectors, such as care work for the sick or elderly? For the most part, robots are expected to replace human workers in specific areas: "They are mostly routine-based jobs (telemarketing, sewing) and work that can be solved by smart algorithms (tax preparation, data entry keyers, and insurance underwriters)" (Thompson, 2014). Robots are not usually considered a threat to workers employed in the service industry, healthcare workers, or therapists. They are not seen, that is, as threats to humancentered, affective forms of labor. As entities like Ellie and Jibo demonstrate, however, this may not remain the case. In Europe, robots are already being used to care for elderly patients. These are robots, however, are really monitoring systems. Rather than being seen as replacements for human contact, these sensors are intended to augment inperson visits, or fill gaps in between them (Turk, 2014). If care robots become more sophisticated, however, could they be used to replace home health aides or other domestic workers? Recently, marginal and oftentimes invisible domestic workers like nannies, home health aides, and housekeepers, who are often underpaid immigrant women of color, have formed unions like Domestic Workers United (formed in 2000). DWU fights for fair wages, benefits, and sick days for these workers, but what if they could be replaced altogether?

In the food service industry, robots may also pose a threat. Now that fast food workers across the nation have called for higher wages and collective bargaining rights, some corporations are looking to technology to make these workers obsolete. Panera Bread, for example, has revealed plans to have self-service ordering kiosks and mobile ordering applications in their restaurants within the next few years (O'Toole, 2014). While the full replacement of low-wage food service industry workers is not likely within the next decade, what about the long-term future? How could labor unions and other labor advocates fight back against automation?

\section{Conclusion}

As has been discussed, intelligent systems have been introduced in a wide variety of sectors and have been associated with both utopian and dystopian discourses about the future of work for human beings. The potential disruptions presented by intelligent systems are not simply a matter of technical mechanisms and social resistance. It's also about scaffolding the right socio-technical infrastructure in which these systems can fit within society. Part of imagining a future with intelligent systems is to understand what types of policies should be put into place to help bridge disconnects between technology advancement and public concerns. 
Tim Hwang and Lea Rosen (2014) assert that we need to develop a "policy-first" approach when it comes to regulating these intelligent systems:

A policy-first analysis proceeds by parsing out different aspects of a single intelligent system, and grouping each aspect with characteristics of other intelligent systems that implicate analogous policy concerns. Under the policy-first approach, the public safety challenges raised by the use of artificial intelligence in medical diagnosis would be rightly categorized alongside the public safety concerns raised by faulty intelligent systems that provide financial or legal advice. Similarly, the fairness concerns raised by medical intelligent systems would be grouped with the fairness challenges raised by the provision of government services with intelligent systems. (p. 10)

While intelligent systems come in many different forms and have the potential to disrupt multiple sectors, legislation is needed in order to encapsulate all of these changes instead of focusing on just one area. It is easy to get caught up in the utopian or dystopian discourses about AI, particularly when new inventions are inspired by older science fiction stories, but we must learn to look past the novelty of intelligent systems and think about how we might begin to regulate them as a whole. In general, how might we being to think about fairness to workers who interact with intelligent systems, or those who fear being replaced by them? What are the legal protections for people who are misdiagnosed or fired by algorithms, and who is accountable?

\section{Acknowledgments}

This document was produced as a part of the Future of Work Project at Data \& Society Research Institute. This effort is supported by the Open Society Foundations' U.S. Programs Future of Work inquiry, which is bringing together a cross-disciplinary and diverse group of thinkers to address some of the biggest questions about how work is transforming and what working will look like 20-30 years from now. The inquiry is exploring how the transformation of work, jobs and income will affect the most vulnerable communities, and what can be done to alter the course of events for the better.

We are grateful to Patrick Davison, Tim Hwang, Rosa Jurjevics, Karen Levy, and Seth Young for their help with different aspects of this project.

\section{Bibliography}

Aschbrenner, Joel. (2014). "Real estate agents pushing legal limits with drone use." The Des Moines Register, July 7, 2014.

http: / / www.desmoinesregister.com/story/news/2014/07/06/drones-commercial-usageillegal-faa-real-estate-realtors-developers / $12262513 /$

Burns, Matt. (2014). “Google Explains How Not To Be A Glasshole.” Tech Crunch, February 18, 2014. http:/ / techcrunch.com/2014/02/18/google-explains-how-not-to-be-a-glasshole/

Calo, Ryan. (2014). "Robotics and the New Cyberlaw." Paper presented at the We Robot Conference at the University of Miami School of Law in Coral Gables, FL, USA. http:/ / robots.law.miami.edu/2014/wp-content/uploads/2013/06/Calo-Robotics-and-theNew-Cyberlaw.pdf 
Canadian Centre for Occupational Health and Safety. (2012). "Health and Safety Report," 10(6). Canadian Centre for Occupational Health and Safety Newsletter. http://www.ccohs.ca/newsletters/hsreport/issues/2012/06/ezine.html

Constine, Josh. (2014). "Uber is About to Launch an API." Tech Crunch, August 12, 2014. http:/ / techcrunch.com/2014/08/12/uber-api/

CNN Wire. (2014). “Will robots replace fast food workers?” CNN Wire, May 22, 2014. http:/ / myfox8.com/2014/05/22/ will-robots-replace-fast-food-workers/

Dzieza, Josh. (2014). "Why robots are getting cuter." The Verge, August 5, 2014. http:/ / www.theverge.com/2014/8/5/5970779/ rise-of-the-adorable-machines

Fehrenbacher, Katie. (2014). "Michael Bloomberg: You can't teach a coal miner to code." Gigaom, April 9, 2014. http:/ / gigaom.com/2014/04/09 / michael-bloomberg-you-cant-teach-a-coalminer-to-code /

Frick, Walter. (2014). "Experts Have No Idea If Robots Will Steal Your Job." Harvard Business Review Blog, August 8, 2014. http:/ / blogs.hbr.org/2014/08/experts-have-no-idea-if-robotswill-steal-your-job/

Hernandez, Brian Anthony. (2014). “Kanye West Fears Paparazzi Drones Might 'Electrocute' His Daughter." Mashable, August 7, 2014. http:/ / mashable.com/2014/08/07/ kanye-west-dronesdaughter-north-west/

Hodson, Hal. (2014). "Meet Jibo, the cute social robot that knows the whole family." New Scientist, July 16, 2014. http:/ / www.newscientist.com/article/dn25881-meet-jibo-the-cute-social-robotthat-knows-the-family.html\#.U-viRkgoPsk

Huffpost Tech. (2014). "Venture Capital Firm Hires Artificial Intelligence To Its Board Of Directors." The Huffington Post UK, May 5, 2014.

http:/ / www.huffingtonpost.co.uk/2014/05/15/artificial-intelligence-boarddirectors_n_5329370.html

Hwang, Tim \& Lea Rosen. (2014). “Toward a Policy_First Framework of Intelligent Systems Regulation." Sent via email to Alex Rosenblat, August 2014.

Kantor, Jodi. (2014). "Working Anything but 9 to 5." The New York Times, August 13, 2014. http:/ / www.nytimes.com/interactive/2014/08/13/us/starbucks-workers-schedulinghours.html?_r=2

Kotler, Steven. (2014). “The Uncanniest Valley: What Happens When Robots Know Us Better Than We Know Ourselves?" Forbes, July 20, 2014. http:/ / www.forbes.com/ sites/ stevenkotler/2014/07/20/the-uncanniest-valley-whathappens-when-robots-know-us-better-than-we-know-ourselves/

Kuncel, Nathan R., David M. Klieger \& Deniz S Ones. (2014). “In Hiring, Algorithms Beat Instinct." Harvard Business Review, May 2014. http:/ / hbr.org/2014/05/in-hiring-algorithmsbeat-instinct/ar/1

Lawler, Ryan. (2014). “Uber Opens its API with 11 Launch Partners, Including OpenTable, TripAdvisors, and United Airlines." Tech Crunch, August 20, 2014. http: / / techcrunch.com/2014/08/20/uber-api-part-deux/

Lee, Matthew. (2007). "Intro to Context-Aware Computing." Retrieved from Carnegie Mellon University department of computer science Web site: http:/ / www.cs.cmu.edu/ jasonh/ courses/ubicomp-sp2007/ slides/12-intro-contextaware.pdf

Levy, Karen. (2014, June). “Beating the Box: Surveillance and Resistance in the U.S. Trucking Industry." Paper presented at Privacy Law Scholars Conference in Washington, DC, USA. 
Lowensohn, Josh. (2014). "Google made a self-driving car, and it doesn't have a steering wheel." The Verge, May 27, 2014. http:/ / www.theverge.com/2014/5/27/5756436/this-is-googlesown-self-driving-car

McCarthy, John. (2007). "Basic Questions," Retrieved from Stanford University Web site: http:/ / www-formal.stanford.edu/jmc/ whatisai/node1.html

McClelland, Mac. (2012). “I Was a Warehouse Wage Slave.” Mother Jones, March/ April 2012. http:/ / www.motherjones.com/politics / 2012/02/ mac-mcclelland-free-online-shippingwarehouses-labor

McNeal, Gregory S. (2014). "Woman Faces A Year In Jail For Beating Drone Operator, Assault Caught On Video." Forbes, June 10, 2014.

http:/ / www.forbes.com/ sites / gregorymcneal / 2014/06/10/ woman-faces-a-year-in-jail-forbeating-drone-operator-assault-caught-on-video/

Moshtagh-Khorasani, Majid, Mohammed-R Akbarzadeh-T, Nader Jahangiri, \& Mehdi Khoobdel. (2009). "An intelligent system based on fuzzy probabilities for medical diagnosis - a study in aphasia diagnosis." Journal of Research in Medical Sciences, March-April 2009. http:/ / www.ncbi.nlm.nih.gov/pmc/articles/PMC3129094/

Newton, Casey. (2014). "Uber will eventually replace all its drivers with self-driving cars." The Verge, May 28, 2014. http:/ / www.theverge.com/2014/5/28/5758734/uber-will-eventuallyreplace-all-its-drivers-with-self-driving-cars

O’Toole, James. (2014). “Robots Will Replace Fast-Food Workers.” CNN Money, September 4, 2014, http:/ / money.cnn.com/2014/05/22/technology/innovation/fast-food-robot/

Paxson, Heather. (2012). The Life of Cheese: Crafting Food and Value in America. Oakland, CA: University of California Press.

Singer, Natasha. (2014). "In the Sharing Economy, Workers Find Both Freedom and Uncertainty." The New York Times, August 16, 2014. http:/ / www.nytimes.com/2014/08/17/technology/inthe-sharing-economy-workers-find-both-freedom-and-uncertainty.html

Smith, Aaron \& Janna Anderson. (2014). "AI, Robotics, and the Future of Jobs." Pew Research Internet Project. http:/ / www.pewinternet.org/2014/08/06/future-of-jobs /

Smith-Spark, Laura \& Carolyn Sung. (2014). "Tracy Morgan sues Walmart over deadly crash; comic released from rehab center." CNN Entertainment, July 15, 2014. http:/ / www.cnn.com/2014/07/12/showbiz/tracy-morgan-crash-lawsuit/

Spiegel, Alix. (2013). "If Your Shrink Is A Bot, How Do You Respond?" NPR Health Blog, May 20, 2013. http: / / www.npr.org/blogs/health/2013/05/20/182593855/if-your-shrink-is-a-bothow-do-you-respond

Takayama, Leila, Wendy Ju, \& Clifford Nass. (2008). “Beyond Dirty, Dangerous and Dull: what everyday people think robots should do." Proceedings of the Human-Robot Interaction Conference. HRI, Amsterdam, NL. http:/ / www-cdr.stanford.edu/ wendyju/publications/hri114takayama.pdf

Thompson, Derek. (2014). “What Jobs Will The Robots Take?” The Atlantic, January 23, 2014. http: / / www.theatlantic.com/ business / archive/2014/01/ what-jobs-will-the-robotstake/283239/

Tufekci, Zeynep. (2014). "Failing the Third Machine Age: When Robots Come for Grandma." Medium, July 22, 2014. https:/ / medium.com/message/ failing-the-third-machine-age$1883 \mathrm{e} 647 \mathrm{ba74}$

Turk, Victoria. (2014). "Robots Are Caring for Elderly People in Europe." Motherboard, VICE, May 6, 2014. http://motherboard.vice.com/read/robots-are-caring-for-elderly-people-in-europe 
Wikipedia contributors. (2014). "Autonomous car, official predictions." Wikipedia, The Free Encyclopedia. Accessed July 4, 2014.

http:/ / en.wikipedia.org/wiki/Autonomous_car\#Official_predictions 